\title{
Concept of workings reuse with application of resource-saving bolting systems
}

\author{
Volodymyr Bondarenko ${ }^{1}$, Iryna Kovalevska ${ }^{1 *}$, Oleksandr Husiev $^{2}$, Vasyl Snihur ${ }^{3}$, and Ildar \\ Salieiev $^{4}$ \\ ${ }^{1}$ Dnipro University of Technology, 19 Yavornytskoho Ave., 49005 Dnipro, Ukraine \\ ${ }^{2}$ PJSC "DTEK Pavlohradvuhillia", MM "Dniprovske”, 76 Soborna Ave., 51400 Pavlohrad, Ukraine \\ 3PJSC "DTEK Pavlohradvuhillia”, MM "Heroiv Kosmosu”, 76 Soborna Ave., 51400 Pavlohrad, Ukraine \\ ${ }^{4}$ PJSC “Donetsksteel” - Metallurgical Plant”, 30 Lesi Ukrainky Blvd, 01133 Kyiv, Ukraine
}

\begin{abstract}
The new support patterns have been revealed for controlling the combinations of the roof rocks strengthening processes in extraction mine workings with combined roof-bolting systems. It has been established that in adjacent roof rocks, by means of a combination of rope bolts and resingrouted roof bolts, an armored and rock plate is formed, the high loadbearing capacity of which is achieved by maintaining the horizontal thrust forces that reduces the concentrations of all the stresses components to a level many times lower than the strength characteristics of the lithotypes. The criterion has been substantiated for assessing the resistance level of roof-bolts as a part of the combined roof-bolting system, which is used for determination of the most important geomechanical factors in terms of the system loading degree. The patterns have been established of a degree of loading the roof-bolts being a part of the combined roof-bolting system from the main influencing geomechanical factors. The calculated expressions have been obtained to determine the needed parameters for effectively strengthening the roof in workings by a combined roof-bolting system. The mine experiment analysis has been performed as well.
\end{abstract}

Keywords: workings, bolting systems, computational experiment, working support

\section{Introduction}

Currently, there is an advanced and ever-growing trend of the gap between the high level of modern technologies in stoping faces and the possibilities of timely preparation for extraction panels mining. The increase in the length of the longwall to $300 \mathrm{~m}$ and the length of extraction panels to $3 \mathrm{~km}$ is one of the widely implemented ways to reduce this gap. The second very effective direction in reducing the volumes of driving and maintenance of site workings (by $1.7-1.8$ times) with high-performance work of production units is to reuse them with stability increase by the rock massif strengthening with combined bolting systems as part of the resin-grouted and rope bolts. This significantly reduces material and labor costs due to border rocks involvement into counteracting to the rock pressure

\footnotetext{
*Corresponding author: kovalevska_i@yahoo.com
} 
manifestations. However, the efficiency of using such combined bolting systems for complex mining and geological conditions can be realized to the full by establishing the patterns of its elements loading in dependence to main geomechanical factors (the depth of development, structure and properties of the rock mass). And, as a consequence, the obtaining on this basis the calculated expressions for determining the constructive, geometric and force rational parameters of support is a very urgent task. The modeling technology comprises the synthesis of a general geomechanical system of two components: a model of coal-bearing massif and a scheme of mine working support setting [1 - 3]. The scheme is performed in two variants: the existing support setting system in compliance with the technical documentation for the extraction working development, which is called the "basic" and an advanced scheme of support setting based on combined systems, substantiated by studies of the rock mass state, the basic support system details and the experience of workings maintenance.

Despite the difficulties in extraction workings maintenance, their reuse in mines of DTEK Energo LLC, and especially in mines of the Western Donbas, is the main direction in the mining operations technology on very thin coal seams with unstable heaving soil; it is based on the formation of a stable rock arch and preservation of its balance, when in the zone of coal-face work influence $[4,5]$.

Application of a method for increasing of the rock massif stability by means of its strengthening in depth around the extraction working by combined bolting systems [6 -8], which consist of the resin-grouted and rope bolts, reduces significantly the material and labor costs. The border rocks of the mine working are involved into counteracting to the rock pressure manifestations. Thus, the objective of our research is substantiation the system parameters of supporting mine workings by resin-grouted and rope bolts.

\section{Efficiency assessment of the strengthening with the roof bolts}

Analysis of trends in the use of roof bolts as part of support setting systems in mine workings has shown an expansion in the sphere and volumes of their application in combination with the resin-grouted and rope bolts for strengthening of the roof rocks as an independent support and in combination with other types of bearing supports [9 -12$]$. These technologies of the roof bolt strengthening are most actively used in layered soft rocks, such as in the Western Donbas. Therefore, it is advisable to assess the influence of strengthening with the roof bolts on the mechanism of the roof rocks structure transformation in the extraction working. The classical theory of beams and plates bending confirms [13] that the maximal horizontal tension stresses (compressive stresses) $\sigma_{Z}$ occur in the surface areas of the beam (plate), and their value is inversely proportional to the squared thickness of a beam (Figure 1).

For example, if to combine two rock layers with roof bolts, then the bending resistivity of the combined layers increases four times, whereas their total resistivity at separate bending of each layer increases only twice. In case of the rock layers separate deformation, the tension stresses have an increased value and, at a significant bending of a layer, they exceed the tensile strength of the rock - the discontinuity in the thickness of a layer begins. In case of the joint deformation of rock layers combined with roof bolts, the section modulus increases, and this causes the reduction of stresses maxima $\sigma_{Z}$, including the tension stresses. The process of tension cracks occurrence and development are reduced and not every alternating bending of the immediate roof, strengthened with roof bolts, leads to the separation into blocks of the combined rock layers. Besides, with increased thickness of the load bearing beam (plate), its rigidity increases, which restricts the value of the layers deflection and reduces the probability of this rock volume destruction, as well as falling of the thrust system into separately descending blocks. Consequently, the quantity of 
interacting elements in the thrust system of roof rocks decreases. And this, according to known rules of multi-hinged load-bearing systems calculation, increases the roof rocks stability - the reaction of their resistivity to the rock pressure increases and the value of descending into mine working cavity decreases.

(a)

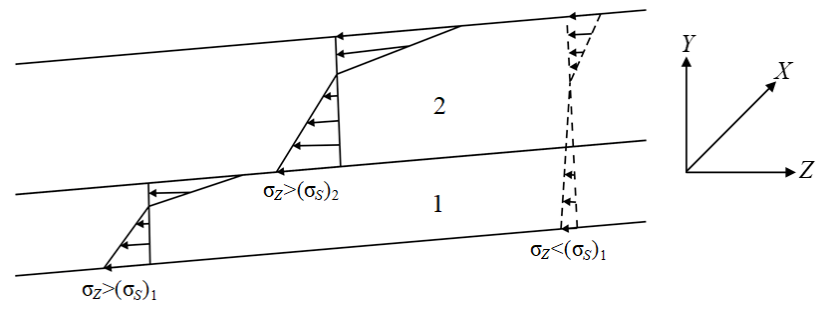

(b)

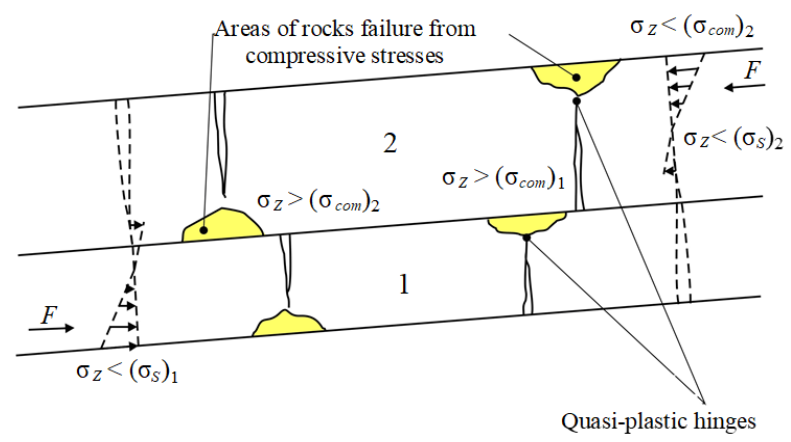

Fig. 1. The schemes of horizontal stresses $\sigma_{Z}$ distribution to thickness of rock layers of the roof (a) and a scheme of stability assessment (b) at their separate ( $\longrightarrow$ ) and joint ( F-deformations, where $\left(\sigma_{S}\right)_{1},\left(\sigma_{S}\right)_{2},\left(\sigma_{c o m}\right)_{1},\left(\sigma_{c o m}\right)_{2}$ are tension and compression stresses of the first and second rock layer.

\section{Setting of the problem and analysis of computational experiments}

The performance of computational experiments on the basis of the finite element method (FEM) was carried out with the use of recommendations of the National Mining University as regard to geomechanical processes modeling of the coal-bearing massif displacement in the vicinity of extraction workings $[14,15]$. The modeling technology comprises the synthesis of a general geomechanical system (Figure 2) from two components: a model of rock mass and a scheme of mine working support. The scheme is performed in two variants: the existing support system in compliance with the technical documentation for the reusable belt working development, which is called the "basic" and an advanced scheme of special designed [16]. In general, based on the research results of the basic support setting system, it is established: the maximal threat to its stability is constituted by the frame prop, especially they are plastically deformed along the whole length from the side of mined-out space; the cap of the frame flattens out with a bend into mine working cavity in the central part and with the occurrence of the limit state $(\sigma=260-290 \mathrm{MPa})$ at the SCP profile top, and in the area of a contact with the central prop of the strengthening support, the plastic deformations develop even more intensively $(\sigma \geq 290 \mathrm{MPa})$; among the most loaded roof bolts is the optional one located in the roof of mine working, under the security band, and, in part, the 
peripheral roof bolts are the most loaded with the appearing of $\sigma_{T}$ steel, whilst the central roof bolts in mine working arch are underloaded; the central prop of the strengthening support (wooden) throughout the entire volume are in the limiting state, but on a contact with the frame root beam - in the superlimiting state. The peculiarity of $\sigma$ distribution along the length of roof bolts indicates the process of their displacement into the mine working cavity together with the strengthened roof rocks, which are stratified more intensively in the border part of mine working and less intensively in the embedded part of the roof bolt length.

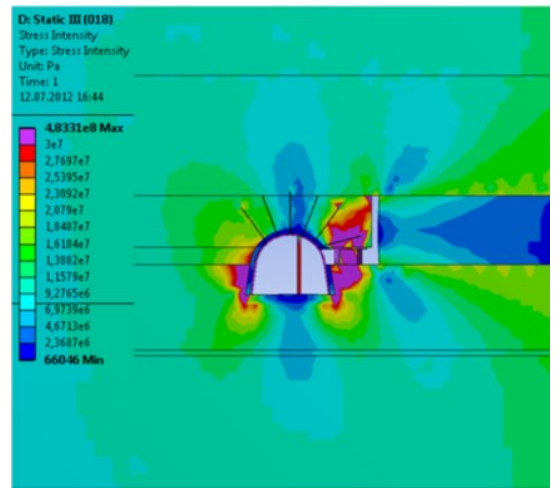

Fig. 2. The field of $\sigma$ stresses intensity under the basic scheme of support setting.

It also follows that the active displacements of the roof rocks extend outwards the roof bolts length of $2.4 \mathrm{~m}$ : the state of the roof from side of the longwall (especially above the security structure) requires not only a thicker reinforcement mesh, but also its deeper distribution. One of the technological solutions to this problem is the setting of rope bolts, which can simultaneously serve as a deeper strengthening of the roof rocks, limiting itsë stratification. Thus, if to set two rope bolts (in increments of $L=1.6-2.0 \mathrm{~m}$, that is, every two frames along the mine working length) symmetrically in a cross-section to 0.8 to $1.0 \mathrm{~m}$ from the vertical axis of mine working with an angle of $70-80^{\circ}$ to the horizontal, they strengthen the roof volume to a width of $7.5-8.0 \mathrm{~m}$. This is sufficient to increase the stability of rock consoles and dimensions restriction of the limit state zone of rocks. Analysis of stresses intensity curves (Figure 3) of the massif surrounding the mine working with the use of a combined bolting system instead of the basic one has shown a variety of changes in the state of adjacent rocks. First, unloading almost does not affect the immediate roof rocks: from the side of mined-out space, a local area with a value $\sigma$ is formed, which corresponds to the virgin massif state; in rocks above the central part of the arch, an area is created with a concentration $\sigma$ of $1.6-2.0$ level from the initial state of the virgin massif. Secondly, the distribution pattern $\sigma$ in the first layer of the main roof (heavy siltstone) indicates the possibility of a partially independent deflection of the main and immediate roof with some horizontal displacements relatively each other caused by restricted flexibility of the rope due to its tensile elongation. It is this possibility (even if limited) of horizontal displacements relatively each other in the immediate and main layers of the roof, which induces the occurrence of a local unloading area in them with dimensions in the section plane up to $0.7 \times 1.0 \mathrm{~m}$. The level of unloading is $0.4-0.8$ from the initial state value of the virgin massif and points to preservation of a part of the horizontal thrust within this local area, above which the siltstone state changes to initial state, and then at half of the rock layer thickness of the main roof the concentration $\sigma$ of $1.2-2.0$ level acts. This concentration characterizes the effect of thrust forces in case when the main roof lower layer resists the deflection, and the absolute values of $\sigma$ are by $1.75-2.91$ times lower than the compressive resistance of siltstone. In adjacent side rocks from the side of coal body another feature is observed in the distribution of $\sigma$ : they are lowered in comparison with the basic variant of support setting. Thus, the concentration $\sigma$ is $1.6-2.0$ to width into massif up to 2.1 
$\mathrm{m}$, which is many times less than compressive resistance of both as the immediate roof rocks, so the coal seam rocks; in soft rocks of the immediate bottom this concentration causes their weakening and provokes the swelling process. If to compare the side bearing pressure when using the combined bolting system, it is by $2-3$ times lower relative to the basic variant of support setting.

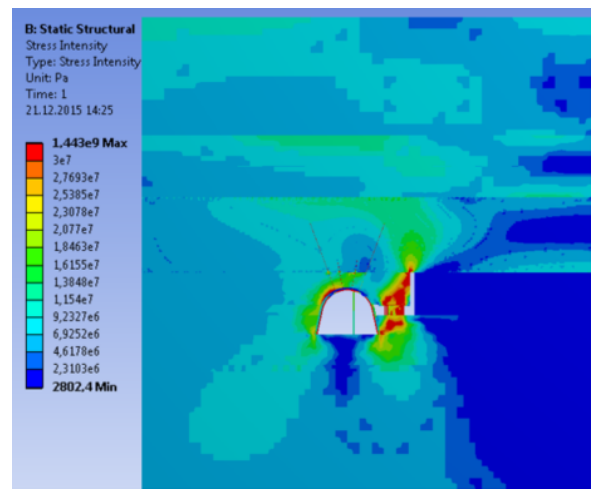

Fig. 3. The field of stresses $\sigma$ intensity distribution when using the combined bolting system.

In such a way, the analysis of the coal-bearing massif state around the working proves conclusively that the application of combined bolting systems enables the more efficient use of the load-bearing capacity of the roof rocks by maintaining the thrust forces between the rock blocks and rock armored plate formation. And this, in turn, by analogy with the "chain reaction" reduces the stress-strain state (SSS) manifestations intensity in sides and bottom of the workings. At the same time, the elements of the support setting system are loaded on $70-90 \%$ of their load-bearing capacity without the formation of the plastic state zones (Figure 4). It is then necessary to determine the quantity of roof bolts, sufficient for the formation of a rock armored plate in the roof, protecting reliably the extraction working from excessive rock pressure manifestations. It is therefore important to outline the range of conditions for the effective application of combined bolting systems based on established patterns of relation the roof bolts loading degree and geomechanical factors characterizing the conditions of the working maintenance. Then, based on the developed general algorithm for search of rational parameters of the combined bolting systems setting and within the general scheme of extraction working maintenance, a range of geomechanical factors has been identified and substantiated. These factors have the greatest effect on the degree of the roof bolts loading: depth $H$ of mine working location, average calculated compressive resistance $R$ of adjacent coal-bearing rocks, the ratio of calculated compressive strength of the coal seam immediate roof rocks to its thickness $R_{1}{ }^{r} / m_{1}{ }^{r}$. To estimate the degree of the roof bolts loading, the appropriate criteria are substantiated: the relative length of the plastic state of the resin-grouted bolts load-bearing element $\Delta$ in the central part of the mine working arch and rope bolts $\Delta_{f, m}{ }^{\text {rope }}$ in the roof from the side of mined-out space and, respectively, of virgin massif. The general pattern (Figure 5) for all the roof bolts within the combined bolting system is in an increase of the relative length of the plastic state segments with the growth of the parameter $H$; all the patterns are close to the linear functions $\Delta(H)$ and $\Delta_{f, m}{ }^{r o p e}(H)$.

There is a different degree of loading of resin-grouted and rope bolts.

The second geomechanical factor affecting significantly the degree of roof bolts loading within the combined bolting system is the parameter $R$ (Figure 6). The general trend for all the roof bolts is in an increase of $\Delta, \Delta_{f, m}{ }^{\text {rope }}$ with a decrease in the parameter $R$, but the dependences $\Delta(R)$ and $\Delta_{f, m}{ }^{\text {rope }}(R)$ differ significantly from each other. The patterns of the parameter $R_{1}^{r} / m_{1}{ }^{r}$ influence on the relative length $\Delta$ and $\Delta_{f, m}{ }^{r o p e}$ are shown in Figure 7. 


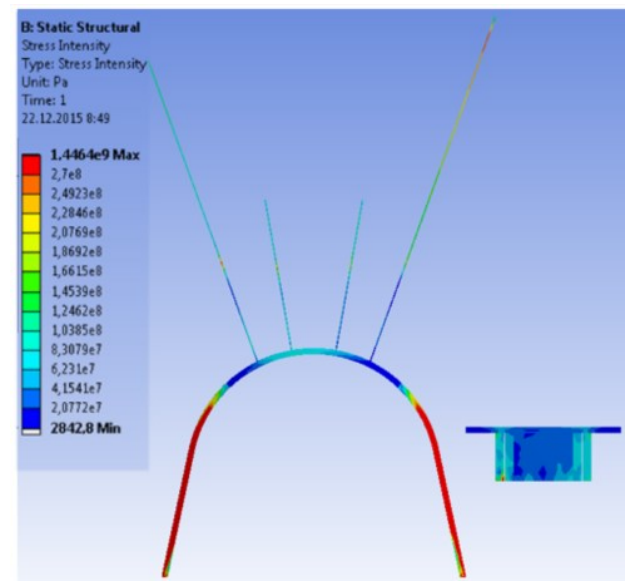

Fig. 4. The field of stresses $\sigma$ intensity in the support when using a combined bolting system.

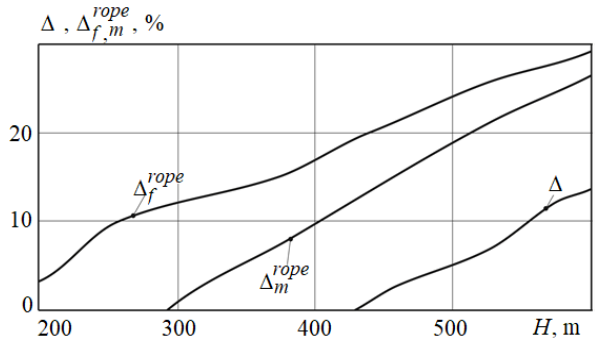

Fig. 5. The curves of influence of the mine working location depth $H$ on the relative length $\Delta$ and $\Delta_{f, m}{ }^{\text {rope }}$ of the plastic state segments of the roof bolts.

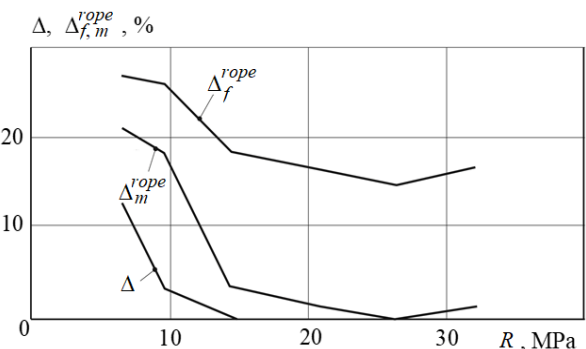

Fig. 6. The curves of influence of the adjacent massif parameter $R$ on the relative length $\Delta$ and $\Delta_{f, m}{ }^{\text {rope }}$.

\section{$\Delta, \Delta f, m, \%$}

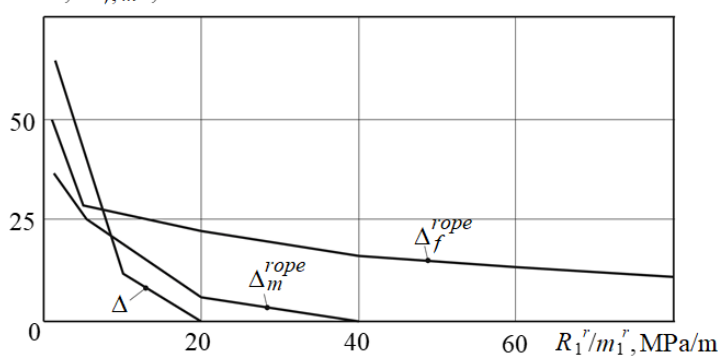

Fig. 7. The curves of influence of the parameter $R_{1}{ }^{r} / m_{1}{ }^{r}$ on the relative length $\Delta$ and $\Delta_{f, m^{r}}{ }^{r o p e}$.

The revealed patterns are the basis for the development of methods for calculating the rational parameters of the bolting system. And this is realized by two conditions: on the one hand, the roof bolts, together with the strengthened roof rocks, should maximally unload the frame support to restrict effectively the cross-section loss in the mine working; on the other hand, the roof bolts in the roof should work with maximum resistivity to rock pressure, that is, they should be set in a sufficient, but minimal quantity.

When determining the relation of the coordinates $x_{i}$ of the resin-grouted bolts setting with geomechanical factors, the patterns of the roof bolts loading degree variation (see Figure $5-7$ ) are used. The resin-grouted bolts are located along the mine working arch 
contour. And it follows from these patterns that the force potential of the resin-grouted bolts in the roof is realized only with an intensive manifestation of vertical rock pressure: $H \geq 400-450 \mathrm{~m}, R \leq 10-15 \mathrm{MPa}$ and $R_{1}{ }^{r} / m_{1}{ }^{r} \leq 15-20 \mathrm{MPa} / \mathrm{m}$. Under these conditions, the resin-grouted bolts actively resist the processes of roof stratification and lowering of the mine working roof rocks that implies an increased density of their setting ( $7-9$ roof bolts). In more favorable mining and geological conditions, the quantity of roof bolts in the roof is significantly reduced (up to 3 to 5 roof bolts); since they remain underloaded and their minimal required quantity in the roof is determined by the search for $x_{i}$ coordinate of each roof bolt location. With a significant underloaded any roof bolts, they are excluded from consideration, while retaining their load results for more loaded roof bolts. At the same time the load, taken up by underloaded roof bolts is considered when increasing the stresses intensity in the loaded roof bolts due to the reserve of resistance, caused by the point and stage of any steel strengthening of the roof bolt's "reinforcement". With the use of the stated approach, the graphs of dependences (Figure 8) were obtained of the coordinates $x_{i}$ of the resin-grouted bolts setting on the parameters $H / R$ and $R_{1}{ }^{r} / m_{1}{ }^{r}$.

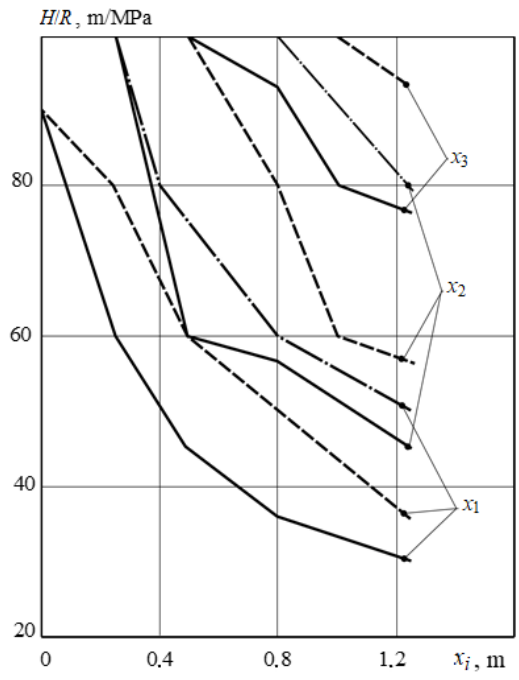

Fig. 8. The relation of the coordinates $x_{i}(i=1,2,3)$ and parameter $H / R:-R_{1}^{r} / m_{1}^{r}=4.8 \mathrm{MPa} / \mathrm{m}$; - $R_{1}{ }^{r} / m_{1}^{r}=10.2 \mathrm{MPa} / \mathrm{m} ; \quad R_{\mathrm{r}}^{r} / m_{1}^{r}=15.6 \mathrm{MPa} / \mathrm{m}$.

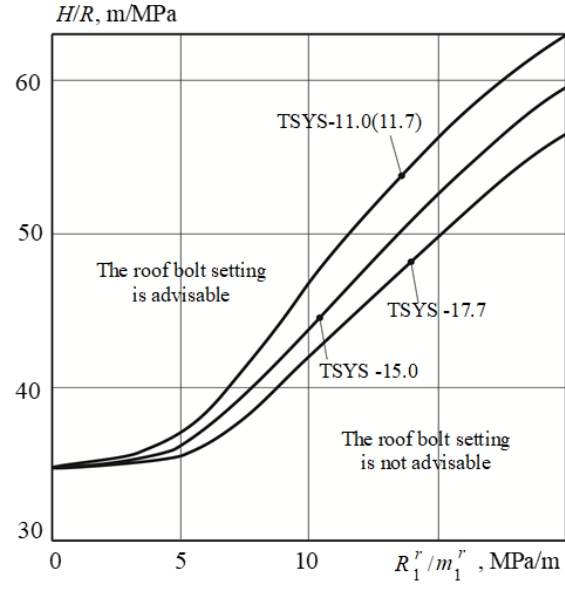

Fig. 9. The curves of application and area of appropriate resin-grouted bolts arrangement.

By way of preliminary calculations and experiment it was found out that placing more than six roof bolts in the central part of the roof is not rational due to their low loading. Then, when a symmetrical scheme for the roof bolts setting, the change in the three coordinates $x_{i}(i=1,2,3)$ has been analyzed depending on the mining and geological conditions. An inverse relation has been established of the coordinates $x_{i}$ with the value of $H / R$ ratio, which is steadily repeated for all the calculation variants, regardless of the roof bolts quantity in the mine working arch. The roof bolts are excluded, for which $x_{i}$ coordinate reaches or exceeds the coordinate of the frame yielding joist location.

In a different way, the coordinates $x_{i}$ are affected by the ratio $R_{1}{ }^{r} / m_{1}{ }^{r}$ : with the roof rock hardness increase, the load on the roof bolts is reduced and it is advisable to decrease their quantity, and this corresponds to an increase in the distance between the roof bolts (the displacement of the coordinates of their setting from joist to spring). The revealed patterns make it possible to obtain a set of regression equations (1) from the calculation of the values $x_{1}, x_{2}, x_{3}$ : 


$$
\begin{gathered}
x_{1}=-5.8 \cdot 10^{-2} R_{1}{ }^{r} / m_{1}{ }^{r} \ln (0.015 H / R-0.52), \mathrm{m} ; \\
x_{2}=10^{-2} R_{1}{ }^{r} / m_{1}{ }^{r}[4.8-10.9 \ln (0.015 H / R-0.52)], \mathrm{m} ; \\
x_{3}=10^{-2} R_{1}^{r} / m_{1}{ }^{r}[12.6-17.2 \ln (0.015 H / R-0.52)], \mathrm{m} .
\end{gathered}
$$

In the adjusted values, the index " 1 " for $x$ stands for the coordinate $x_{1}$ of the roof bolt setting with the minimal distance from the vertical axis of the mine working, and the index " 3 " - with the maximal distance. If the value $x_{3}$ exceeds the horizontal coordinate of the yielding joist location in the frame support with corresponding size of the mine working cross-section, then the end roof bolt is excluded from the scheme of the roof bolts setting in the arch. By a similar way, the expediency is considered of the roof bolts setting in the arch with coordinates $x_{2}$ and $x_{1}$. Then, in some area of geomechanical parameters ratio, there is no need to set the resin-grouted bolts along the arch contour in place between the yielding joists of the frame. The main point of this statement is that the roof with increased stability is not able to load the resin-grouted bolts up to the level of their active work on resistivity to vertical rock pressure. There is an effect of a relatively restricted length of the resin-grouted bolts: at this length, the difference in the roof displacement in the area of the roof bolt shank and in place of its joist does not create tensile forces in the roof bolt's "reinforcement", which are comparable to the yield point of steels. At the same time, with an increased length of the roof bolts, the difference in these displacements increases that induces their full loading and effective resistivity to the roof lowering even under conditions of its relative stability. Thus, there is an area of mining and geological conditions, when a low efficiency is observed of the roof rocks strengthening with resin-grouted bolts within the central part of the mine working arch. To determine the boundaries of this area, the following ratios (2) have been obtained of geomechanical parameters for the most commonly used types of cross-sections $S$ of extraction workings with TSYS support:

$$
\begin{array}{ll}
S=11.0(11.7) \mathrm{m}^{2} & H / R \leq 34.7+66.7 \exp \left(-17.2 m_{1}{ }^{r} / R_{1}{ }^{r}\right), \mathrm{m} / \mathrm{MPa} \\
S=15.0 \mathrm{~m}^{2} & H / R \leq 34.7+66.7 \exp \left(-19.8 m_{1}{ }^{r} / R_{1}{ }^{r}\right), \mathrm{m} / \mathrm{MPa} \\
S=17.7 \mathrm{~m}^{2} & H / R \leq 34.7+66.7 \exp \left(-22.4 m_{1}{ }^{r} / R_{1}^{r}\right), \mathrm{m} / \mathrm{MPa} .
\end{array}
$$

When a value $H / R$ is less than calculated by the above formulas, it is not recommended to set the resin-grouted bolts in the central part of the arch; otherwise, their quantity is determined by $x_{i}$ calculation formulas. To assess promptly the practicability of the resingrouted bolts arrangement in the central part of the mine working arch, the graphs are constructed (Figure 9).

\section{Results of the belt entry underground trials at an experimental site of the combined bolting system setting}

The belt entry was reused as ventilation during the coal-face work at an adjacent extraction site. The scheme of the entry support setting is shown in Figure 10a. In the lower part of its length the experimental site is located with the recommended scheme of support setting (Figure 10b).

It has been established that the combination of the resin-grouted and rope bolts creates strengthening not only of the immediate but also of the main roof, binds the rock layers into a single rock armored construction with high thickness (not less than $4-5 \mathrm{~m}$ ), capable to take up and resist to increased rock pressure and, thus, to protect the frame support against excessive loads. The formed rock armored plate extends the area of its supports in the mine working sides, and its high load-carrying capacity and rigidity allows not only to reduce the 
load on the frame, but also to reduce the rock pressure manifestations. And this restricts the horizontal displacements of the border rocks in mine working sides and the intensity of the swelling process development in the bottom rocks. The visual observations (Figure 11) and measurements showed that the shape of the TSYS-15.0 support frame and its elements (cap and prop stays) was not almost changed outside the coal-face work influence zone in comparison with the originally set; the frame yielding joists did not act and the overlap value of the cap and the frame were also in the primary position about of $350-420 \mathrm{~mm}$. This indicates the restricted load of the frame till its pliable mode of operation. These observations indirectly indicate a high efficiency of the rock armored plate operation in the roof of the entry: its load-bearing capacity makes it possible to unload the frame support from excessive rock pressure by taking up of the greater its part.

(a)

TSYS- 11.7

$S_{\text {in }}=10.0 \mathrm{~m}^{2}$

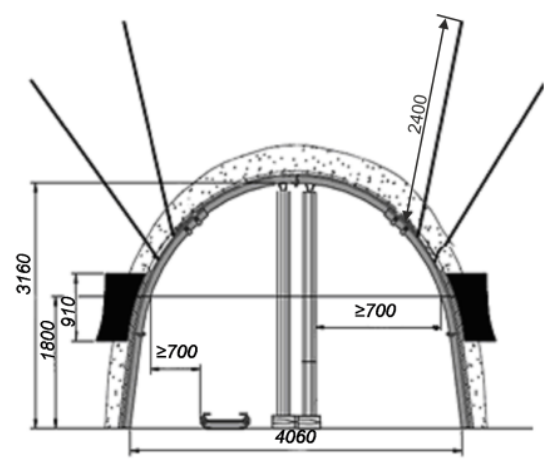

(b)

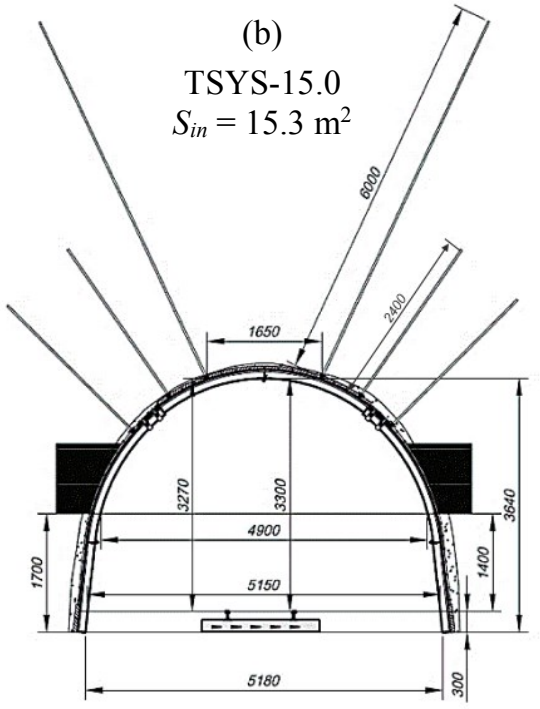

Fig. 10. Schemes for the belt entry support setting with the use: a) roof bolt support (basic), and b) combined bolting (recommended).

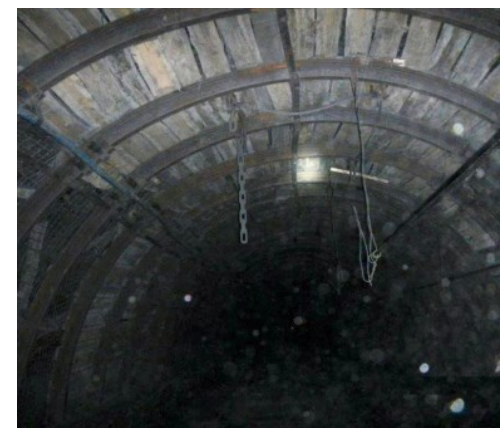

Fig. 11. Fragment of the belt entry state at an experimental site.

\section{Conclusions}

In general, summarizing the results of mine observations, it is necessary to note the satisfactory state of the belt entry after the first longwall drivage. Its state allows reusing it as ventilation when mining the adjacent extraction site, if to carry out the moderate repair 
and recovery works in respect of the frame support, side and roof. A positive result has been achieved through the use of a combined bolting system in the mine working roof.

The authors express their gratitude to senior management of PJSC "DTEK Pavlohradvuhillia" and Mine Administration for the assistance in research development.

\section{References}

1. V. Bondarenko, I. Kovalevs'ka, V. Fomychov, Geomechanical Processes during Underground Mining: School of Underground Mining, 7-13 (2012) doi:10.1201/b13157-3

2. J. Blachowski, P., Stefaniak, Min. Sc. J. 20 (2013)

3. Z. Niedbalski, P. Małkowski, T. Majcherczyk, Tunnelling and Underground Space Technology, 74, 41-59 (2018) doi: 10.1016/j.tust.2018.01.003

4. V. Bondarenko, V. Cherniak, F. Cawood, V. Chervatiuk, Min. of Miner. Dep. J. 11, 2 (2017)

5. V. Bondarenko, I. Kovalevska, G. Simanovish, M. Barabash, V. Snihur, O. Gusiev, The combined bolting systems for repeated use of mine workings, EDP Sciences, LizunovPres, (2017)

6. I. Kovalevska, M. Barabash, O. Husiev, V. Snihur, E3S Web of Conf., 60 (2018)

7. W. Masny, S. Prusek, G. Mutke, G., Proc. Eng. J. 191 (2017)

8. M. Madziarz, Min. Sc. J. 22 (2015)

9. J. Blachowski, Min. Sc. J. 22 (2015)

10. I. Kovalevska, M. Barabash, O. Gusiev, Min. of Miner. Dep. J. 10, 1 (2016)

11. T. Majcherczyk, Z. Niedbalski, P. Malkowski, L. Bednarek, Min. Sc. J. 59, 3 (2014)

12. P. V. Grechishkin, A. S. Pozolotin, D. F. Zayatdinov, V. N. Sharov, Min. J. 8 (2015)

13. Resistance of materials, Edited by G.S. Pisarenko, EDP Sciences, Higher School, (1979)

14. V. Bondarenko, I. Kovalevska, H. Symanovych, M. Barabash, V. Snihur, E3S Web of Conf., 66 (2018)

15. V. Bondarenko, M. Hardygora, H. Symanovych V. Sotskov, V. Snihur, Min. of Miner. Dep. J. 10, 3 (2016)

16. Kovalevska, I., Zhuravkov, M., Chervatiuk, V., Husiev, O., \& Snihur, V., Min. of Miner. Dep. J. 13, 3 (2019) 